11. Życzyńska A. The primary energy factor for the urban heating system with the heat source working in association / A.Życzyńska // Eksploatacja i niezawodność. - 2013. - Vol. 15, № 4. - Pp. $458-462$

$$
\text { Надійшла до редакиії 27.07.2016 p. }
$$

Мальований Мирослав, Жичинська Анна, Диш Гәжегож. Вплив способу забезпечення будинку енергією на величину річної потреби у невідновлюваній первинній енергії

Розглянуто вплив використання відновлюваних джерел енергії на величину річної потреби кінщевої енергії і первинної невідновлюваної енергії, на прикладі громадських будівель. Проаналізовано кілька варіантів технічно можливих рішень із постачання будинків неві уого водопосачн

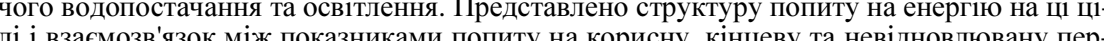

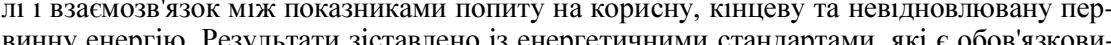
вин за енергі. Результал зї м за польскими нормативними техннчо-будівелними вимотам.. Розрахунки виконао відповідно до європейських стандартів і обов'язковог одологією оцінки енергетичної ефективності будівлі.

Ключові слова: енергоефективність будівлі, поновлювані джерела енергії, кінцева енергія, первинна енергія.

Malovanyy Myroslav, Zyczynska Anna, Dys Grzegorz. The Effect of Energy Supply Choices for Households on the Annual Demand for Non-renewable Primary Energy

The article studies the impact of renewable energy use on the value of the annual needs of final energy and primary non-renewable energy on the example of public buildings. Severa technically possible solutions were analyzed that cover a supply of homes with non-renewable and renewable energy sources for heating, hot water and lighting. The structure of energy demand for this purpose and the relationship between indicators of demand for useful, final and non-renewable primary energy was displayed. The results were compared with the energy standards of legal technical and building requirements in Poland. Calculations were made 作 according to the European standards and followed the mandatory methodology of energy

Keywords: energy efficiency of buildings, renewable energy, final energy, primary energy.

\section{УДК 621.317.089.6}

\section{ОСОБЛИВОСТІ МЕТРОЛОГІЧНОЇ ПЕРЕВІРКИ КОМПОНЕНТ КІБЕР-ФІЗИЧНИХ СИСТЕМ}

\section{О.М. Олеськів ${ }^{1}$, І.П. Микитин}

Проаналізовано особливості функціонування кібер-фізичних систем і їх компонент. Розглянуто класифікацію первинних перетворювачів за типом вихідного сигналу та можливості під'єднання первинних перетворювачів до кібер-фізичних систем. Враховуючи результати проведеного аналізу характеристик кібер-фізичних систем i ix компонент, запропоновано багаторівневу віддалену метрологічну перевірку кібер-фізичних систем, за якою компоненти кібер-фізичної системи можуть перевірятися за вимогою інтелектуальних первинних перетворювачів, підсистем, головної підсистеми керування або людини.

Ключові слова: засіб вимірювання, програмне забезпечення, метрологічна перевірка, кібер-фізична система, вбудована система керування, інтелектуальний первинний перетворювач.

мол. наук. співроб. О.М. Олеськів - НУ "Львівська політехніка"; ${ }^{2}$ проф. І.П. Микитин, д-р техн. наук - НУ "Львівська політехніка"
Постановка задачі. На сьогодні інформаційні технології проникають практично у всі сфери людської діяльності і вони є найважливішим фактором інновацій. Об'єкти із вбудованими системами керування (ВСК), які об'єднані один з одним через глобальні мережі, виконують багато нових функцій та дій, що дають змогу частково або повністю усунути людину з процесу діяльності. 3 кожним роком реальний і віртуальний світи стають дедалі ближчі один до одного, утворюючи технічну базу кібер-фізичних систем (КФС) [1]. КФС, як правило, є складними системами, компоненти яких можуть знаходитися на великій відстані одна від одної. Вони об'єднують інформаційні, програмні, електронні, оптичні, механічні та інші фізичні компоненти, які "спілкуються" через Інтернет у режимі реального часу. КФС опрацьовують інформацію і виконують функції моніторингу та управління обладнанням. Інфраструктура КФС в основному складається з підсистем, електронні компоненти яких реалізуються через ВСК [2], що отримують інформацію про навколишнє середовище за допомогою первинних перетворювачів (ПП) та засобів вимірювання (ЗВ) і можуть впливати на нього через виконавчі механізми (рис. 1). Враховуючи широке застосування мікропроцесорної та мікроконтролерної техніки, основне опрацювання результатів вимірювання, а саме усереднення, апроксимація, фільтрація, інтерполяція, перетворення Фур'є тощо, реалізуються переважно програмним способом.

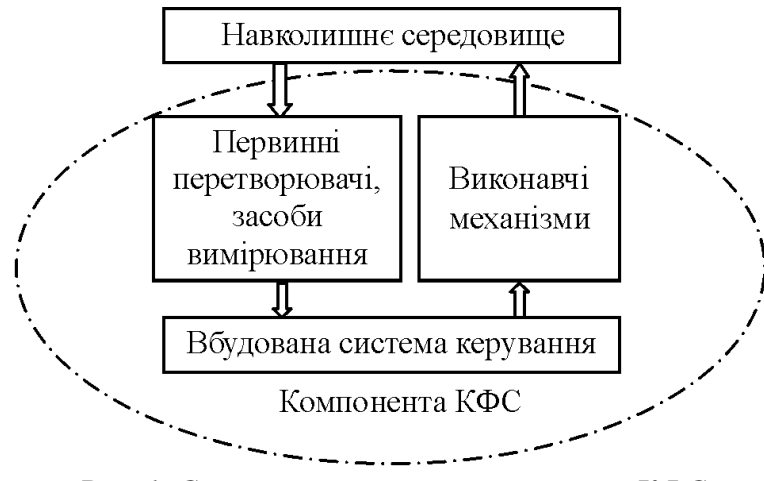

Рис. 1. Структурна схема компоненти КФС

Якщо вимірювальна інформація некоректно відображає характеристики об'єкта зовнішнього середовища (похибки результатів вимірювання перевищують допустимі значення), то дія виконавчих механізмів на об'єкт може бути неправильною. Це може призвести до некоректного функціонування КФС та небажаних наслідків, а інколи і до небезпеки життю людини. Тому для забезпечення правильного функціонування компонент КФС актуальним є розроблення методів, методик та засобів віддаленої метрологічної перевірки первинних перетворювачів, засобів вимірювання та програмного забезпечення.

Аналіз можливості метрологічної перевірки ПП та 3В кібер-фізичних систем. На рис. 2 представлено структурні схеми під'єднання ЗВ електричних величин, ЗВ неелектричних величин та ПП, що мають інтерфейс передавання даних, до компоненти КФС. 


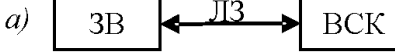

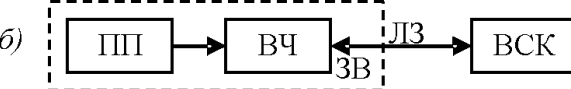

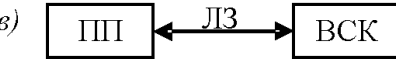

Рис. 2. Структурні схеми під'єднання: а) $3 В$ електричних величин; б) $3 В$ неелектричних величин; в) ПП до компоненти КФС, де $3 B-$ засіб вимірювання; ЛЗ - лінія зв'язку; ВСК - вбудована система керування; ПП - первинний перетворювач; ВЧ- вимірювальна частина

Для метрологічної перевірки ЗВ електричних величин (вольтметри, амперметри тощо), потрібно на вхід подати зразковий сигнал. Існує низка зразкових засобів відтворення напруги, струму, частоти тощо [3], які мають малі розміри і можуть бути інтегровані у КФС. Якщо перевіряється ПП, то на вхід потрібно подати відповідну фізичну величину відомого значення. У більшості випадків для цього потрібне складне та громіздке обладнання, наприклад для перевірки ПП температури потрібно мати реперні точки температури, високоточні термостати і т. ін. Тому віддалена метрологічна перевірка ЗВ електричних величин $\epsilon$ набагато простішою порівняно з ПП. Окрім цього, метрологічну перевірку ПП не завжди можна провести віддалено.

Для віддаленої перевірки ПЗ кібер-фізичні системи підходять якнайкраще, оскільки вони з'єднані з Інтернетом і доступ до них, а отже і до ПЗ, що їх обслуговує, $є$ наявним. Потрібно тільки забезпечити певний програмний сервіс, який дає змогу запустити процес перевірки. 3 іншого боку, цікавим є проведення аналізу можливості під'єднання ПП до ВСК, що дало би змогу істотно спростити вимірювальну частину КФС. На рис. 3 представлено класифікацію ПП за типом вихідного сигналу.

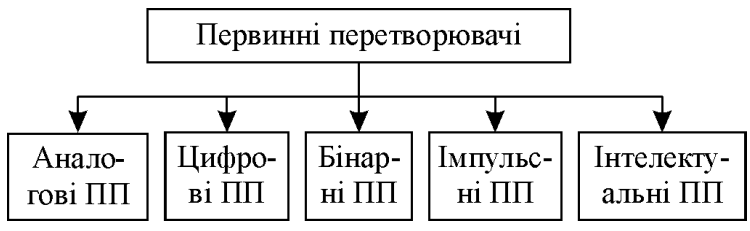

Рис. 3. Класифікація ПП за типом вихідного сигналу

Вихідним сигналом аналогового ПП є неперервна фізична величина (переважно електрична). Перевагою аналогових ПП є простота їх реалізації. Недоліком $\epsilon$ те, що для підключення таких ПП до вимірювальної схеми потрібно використовувати додаткові засоби вимірювальної техніки [4]. Цифрові, бінарні та імпульсні ПП можна безпосередньо підключити до ВСК, якщо вона має цифровий та частотний вхід. Інтелектуальні ПП легко підключаються до ВСК з використанням протоколів промислових мереж Profibus, Foundation Fieldbus та ін.

Інтелектуальні первинні перетворювачі (ІПП) мають низку властивостей, які істотно відрізняють їх від інших видів ПП. Вони можуть автоматично обирати діапазон вимірювання, проводити алгоритмічну корекцію результатів ви342

Збірник науково-технічних праць мірювання, працювати в режимі діалогу з центральною системою управління, приймати команди, передавати результати вимірювання в цифровій формі, а також аварійні повідомлення тощо. ІПП можуть проводити самоналаштування, самодіагностику та самоперевірку [5].

ІПП здійснюють необхідні перетворення вимірювальної інформації та математичне опрацювання результатів вимірювань. Тому використання ІПП дає змогу звільнити ВСК від збереження та опрацювання значної кількості проміжних даних. Враховуючи зазначене вище, оптимальним є використання ІПП у КФС.

Багаторівнева метрологічна перевірка КФС. Метрологічна перевірка КФС є достатньо складною процедурою, враховуючи той факт, що кібер-фізичні компоненти, що об'єднуються в одну систему для виконання певної задачі, можуть розташовуватися у будь-якому куточку земної кулі. Враховуючи таку специфіку КФС, як "засобу вимірювання", запропоновано багаторівневу метрологічну перевірку КФС. Метрологічна перевірка КФС має відбуватися на всіх етапах функціонування, розпочинаючи з перевірки первинних перетворювачів контролюючими компонентами КФС та самоперевірки інтелектуальних первинних перетворювачів і закінчуючи загальною перевіркою КФС, яка задається контролюючою особою, якщо виникли сумніви щодо коректності функціонування КФС або прийшов час планової перевірки КФС.

На основі проведеного аналізу запропоновано багаторівневий процес перевірки КФС (рис. 4). Ініціювати перевірку будь-яку із компонент може сама компонента, компонента вищого рівня або людина.

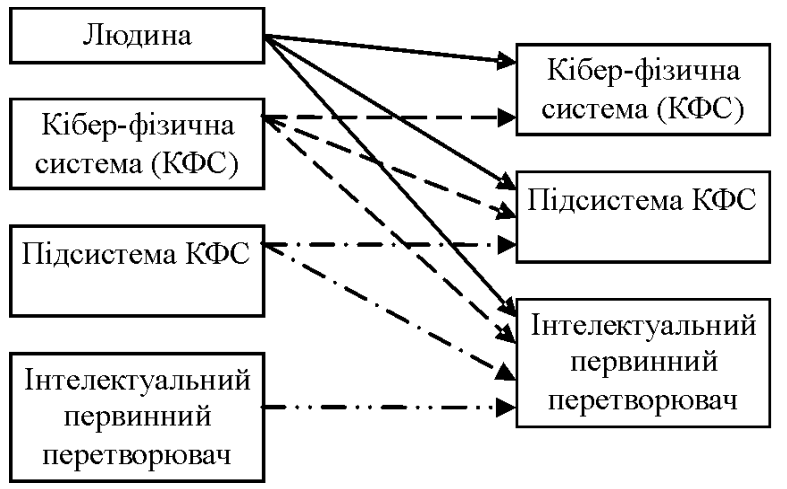

Рис. 4. Багаторівневий процес перевірки КФС

Висновки. На основі розглянутої класифікації ПП зроблено висновок, що у КФС найдоцільніше використовувати інтелектуальні первинні перетворювачі, оскільки вони не вимагають застосування додаткових засобів вимірювальної техніки; здатні самостійно проводити основні опрацювання результатів вимірювання, самоналаштування та самодіагностику, працюють 3 різноманітними інтерфейсами передавання даних тощо. ІПП можуть проводити періодичну метрологічну перевірку своїх ПП, використовуючи вбудовані міри фізичних величин.

4. Інформашійні технології галузі 
Теревірку програмного забезпечення КФС можна реалізувати віддалено, оскільки КФС з'єднані з Інтернетом. Потрібно тільки забезпечити певний програмний сервіс, який дає змогу запустити процес перевірки.

Враховуючи результати проведеного аналізу характеристик КФС та їх компонент, запропоновано багаторівневу віддалену метрологічну перевірку КФС. За запропонованим алгоритмом компоненти КФС можуть перевірятися за вимогою будь-якої компоненти, підсистеми або системи загалом. Також процес метрологічної перевірки може ініціювати людина, у випадку, якщо є підозра у некоректній роботі КФС або прийшов час планової перевірки КФС.

\section{Література}

1. Cyber-physische Systeme. [Electronic resource]. - Mode of access http://www.enzyklopaedieder-wirtschaftsinformatik.de/wi-enzyklopaedie/lexikon/informationssysteme/SektorspezifischeAnwendungssysteme/cyber-physische-systeme. $-89 \mathrm{c}$.

2. Нєнов О.Л. Проектування вбудованих комп'ютерних систем / О.Л. Нєнов. - Одеса, 2008

3. Дорожовець М. Основи метрології та вимірювальної техніки / М. Дорожовець В. Мотало, Б. Стадник, В. Василюк, Р. Борек, А. Ковальчик. - Т. 1. Основи метрології. - Львів Вид-во НУ "Львівська політехніка". - 2005. - 532 с.

4. Поліщук Є.С. Метрологія та вимірювальна техніка / Є.С. Поліщук, М.М. Дорожовець, В.О. Яцук, В.М. Ванько, Т.Г. Бойко. - Львів : Вид-во "Бескид Біт", 2003. - 544 с.

5. Mahajan Ajay. Physical and Virtual Intelligent Sensors for Integrated Health Management Systems / Ajay Mahajan, Christopher Oesch, Haricharan Padmanaban, Lucas Utterback, Sanjeev Chitikeshi, Fernando Figueroa // International journal on smart sensing and intelligent systems, September. - 2012. - Vol. 5, No. 3. - Pp. 559-575

Надійшла до редакиії 15.09.2016 p.

Олеськив О.М., Микитин И.П. Особенности метрологической проверки компонентов кибер-физических систем

Проанализированы особенности функционирования кибер-физических систем. Рассмотрена классификация первичных преобразователей и возможности их подключения к кибер-физическим системам. Учитывая результаты проведенного анализа характерисиик кибер-физичесии систем и их компонентов, предложена многоуровневая отдален-

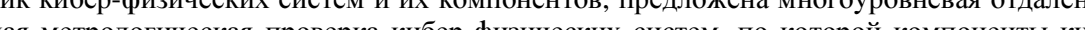
ная метролопи сои проверка кибер-физиеских сисем, по которй комиоенты кибер-физической системы могут проверяться по требованию интеллектуальных первичных преобразователей, подсистем, главной подсистемы управления или человека.

Ключевые слова: средство измерения, программное обеспечение, метрологическая проверка, кибер-физическая система, встроенная система управления, интеллектуальный первичный преобразователь.

Oleskiv O.M., Mykytyn I.P. The Features of Metrological Verification of Cyber-Physical Systems

This article presents the features of functioning the cyber-physical systems and their components. The analysis opportunity of sensors possible accession to embedded system control is examined. The classification by the sensors output signal type is considered. On the basis of the sensors classification concluded that the cyber-physical systems is most expedient to use intelligent sensors. According to the results of the analysis of the cyber-physical system and those components characteristics, a multilevel remote metrological verification of cyberphysical systems is proposed.

Keywords: measuring instrument, software, verification, cyber-physical system, embedded system control, intelligent sensor.

\section{УДОСКОНАЛЕННЯ АЛГОРИТМУ ВИЗНАЧЕННЯ "НАСИЧЕНОГО}

БЛОКУ" У ЗАДАЧІ ПАРАМЕТРИЧНОЇ ІДЕНТИФІКАЦІ

ІНТЕРВАЛЬНОЇ СИСТЕМИ ЛІНІЙНИХ АЛГЕБРИЧНИХ РІВНЯНЬ

\section{I.С. Олійник ${ }^{1,2}$}

Розв'язано задачу верифікації методу параметричної ідентифікації інтервальної системи лінійних алгебричних рівнянь (ІСЛАР) для різних початкових умов, зокрема, залежно від структури та кількості невідомих параметрів моделі; проаналізовано мето обчислення оцінки розв'язків інтервальної системи лінійних алгебричних рівнянь, шляхом заміни усієї системи "насиченим блоком", сформованим із іiі інтервальних рівнян хом заміни усієі системи "насиченим блоком", сформованим із ї інтервальних рівнянь; удосконалено алгоритм визначення "насиенего блоку" у задачі параметричноі ідентифікаціі інтервальної системи лінійних алебричих рівняь у заци " ки вимірювання та показано ефективність рикладів.

Ключові слова: інтервальна система лінійних алгебричних рівнянь (ІСЛАР), редукція, еліпсоїдна оцінка, "насичений блок", "зашумлений" інтервал, абсолютна похибка, відносна похибка

Вступ. Для побудови математичних моделей статичних систем застосовують інтервальний та стохастичний підходи. У рамках інтервального підходу вирізняють розв'язування задач з точними та неточними (інтервальними) даними. Для того, щоб розв'язати задачу з неточними даними, потрібно на основі інтервального аналізу побудувати рівняння, сформувати із них інтервальну систему лінійних алгебричних рівнянь (ІСЛАР) та знайти її розв'язки [1]. Відомо [2], що розв'язки ІСЛАР отримують у вигляді деякої множини, оцінивши яку, можна побудувати інтервальну модель. Серед способів оцінювання множини розв'язків ІСЛАР є, наприклад, метод локалізації області розв'язків багатовимірним еліпсоїдом [3]. Необхідною початковою умовою для роботи цього методу $є$ сформований набір інтервальних рівнянь, кількість яких дорівнює кількості невідомих параметрів моделі. Такий блок рівнянь прийнято називати "насиченим блоком" [1]. Як правило, ІСЛАР містить більше рівнянь, ніж кількість параметрів моделі, тому для знаходження "насиченого блоку" використовують метод редукції, алгоритм якого наведено у праці [4]. Результатами досліджень, опублікованих у праці [4] доведено, що проблемною ітерацією методу редукції є вибір початкового набору інтервальних рівнянь у такий спосіб, щоб забезпечити мінімальні розміри області локалізації множини розв'язків усієї ІСЛАР. Для вирішення цієї проблеми автори [4] запропонували метод формування субоптимального "насиченого блоку" та його застосування для задачі прогнозування генерованої електроенергії малою гідроелектростанцією. Однак актуальною залишається задача верифікації цього методу для різних початкових умов, зокрема, залежно від структури та кількості невідомих параметрів моделі, що і є метою цього дослідження.

Постановка задачі. Залежність між "виходом" та "входами" для статичної системи описують у вигляді алгебричного рівняння [2]

аспір. І.С. Олийник - Тернопільський нашіональний економічний університет; наук. керівник: проф. М.П. Дивак, д-р техн. наук - Тернопільський національний економічний університет. 4. Інформаційні технології галузі 345 